\title{
PSYCHE.
}

\section{THE BIBLIOGRAPHY OF ENTOMOLOGY.}

\author{
ANNUAL ADDRESS OF THE RETIRING PRESIDENT OF THE CAMbridge ENTOMO- \\ LOGICAL CLUB, I I JANUARY I884.
}

\section{Fellow Members of the Cambridge} Entomological Club:-

I thank you for the honor you were pleased to confer upon me a year ago, in electing me to be your president, an office which to my regret I could fill only in name. I look upon this action of yours as a recognition of my interest in your work and of my earnest endeavors to promote it. My absence from your meetings has not weakened my devotion to the cause which under your auspices I have sought, during the last ten years, to advance.

Ten years of the life of the club have expired, in which the membership of the club has enlarged and grown in influence. A bright future is before us if we only strive in unison to carry out the purposes for which our club was formed, in the most liberal spirit, giving, and trusting for the returns.

I need not dwell upon retrospect nor prophecy. You know the past, and you have the future in your own control.

I welcome this opportunity, dictated by custom and by your laws, to express my thoughts upon that part of our work as a club with which I have been most concerned. It will not seem to you unnatural for me to speak of the Bibliography of entomology, its purposes and its methods. I will not go into its history, for I prefer rather to consider its future.

We are fortunate in having in our midst and reckoning as one of our number the prince by excellence of the bibliographers of entomology. We count also amongst our members others who have rendered efficient service in this useful and laborious art. One can hardly think of the Cambridge entomological club without thinking of Psyche or of Psyche without thinking of its Bibliographical record. We are therefore prepared in an especial manner to appreciate the importance of bibliographical work as applied to the promotion of science.

The need of such work is evidently felt in these days more than ever before. Since we entered upon our work we have seen bibliographical departments established as an important feature in 
many periodical publications, and some such publications established, as Psyche was, mainly for the sake of their bibliographical departments.

Bibliography is not a science and yet without it the sciences would fare hardly in these times. By it the hidden treasures of acquired knowledge are brought to light. Without it the advance of knowledge would be slow. The ever increasing mass of literature is a wilderness, which no one can traverse throughout, into which few can penetrate deeply, in whose recesses are scattered, with little order, the gathered riches of innumerable workers. He who would not spend his life in doing anew what has been done before him, and often well done, must have access to these acquired stores. Without guides he would become lost, he would find little of that for which he seeks and in the search would lose his time and his way. The index is to the traveler in this wilderness more than the compass to the mariner. It is the guiding hand which leads him from store to store, and places at his disposal all that he wants, or points out to him the empty coffers yet to be filled. Thus are his labors spared and his strength saved for the work that is yet to be done.

I presume that you all are bibliographers, in varied degrees. You have your several studies, and you make your several indices in relation thereto. You are interested to promote the formation of indices of which you may make use, or by which you may render service to others. I have labored long, as you know, to construct a bibliogra- phy, not so much of any specialty in entomology, as of the subject as a whole.

We have many bibliographical publications at our service now, for the record of current literature. Such works of frequent issue as the Zoologischer anzeiger and the Naturae novitates serve an excellent purpose for temporary use. By them little of value escapes mention. Their form and style are not suited, however, to the characteristics of a permanent and comprehensive bibliography. In their bibliographical department they are little more than lists of writings, without those references to reviews, extracts and reprints, which serve for the history of literature, and which have a more than bibliographical value. They are not adapted for ready reference by means of indices, and indeed hardly pretend to be more than temporary guides to current literature, for the especial benefit of those workers who are ever tumbling over each other in their haste to get at the latest development of science, and to move forward.

The annual records, such as the Zoological record and the Zoologischer jahresbericht, are more than bibliographies in their essential features, but less in others. They too give lists of titles, but without the bibliographical descriptions. The bibliography, such as it is, is almost buried in the mass of the reviews. These works are not so much guides to literature as contributions to it, themselves requiring guides. They treat of the substance of the literature more than of its form, and this so copiously that in the course of years 
they become like forests themselves, the trees indeed planted in rows, but those of one kind so far apart and interspersed with others, that they can only be found by a tedious search.

I do not wish to seem to find fault with these works. I recognize their value for the purposes of their being. I only say of them that they have not certain characteristics which they do not pretend to have. We have yet to find the bibliography that we need, permanent, complete, limited to bibliographical simplicity and convenient of reference.

For the early literature there is no need to attempt to improve upon Hagen's Bibliotheca entomologica. ${ }^{1}$ My remarks apply to literature subsequent to that there recorded, including such omissions from and corrections of that work as occasion may present. The time may come in which a supplement to that work will be published, in some similar form, supplanting all lesser bibliographies, as that has supplanted all earlier ones. Until that time the best that we can do is to form a current bibliography, upon a simple and uniform plan, adapted to serve all the varied purposes which are to be sought in such a work. It may seem superfluous for me to attempt to describe the principles upon which I think such a work should be constructed.

You have granted me so great liberty in the editorial management of Psyche that I have been enabled, as improvements in the form of the bibliographical

1Psyche, Rec., no. 3306. record have been suggested, to put them into practice. I am largely indebted to my principal colaborer in the editorship for many of these improvements. Many changes have been made and probably many others will be made, but the essential features have so far remained the same throughout. Hagen's Bibliotheca served as a model in the beginning, and except in detail little change has been made since.

It is useless in a current bibliography to preserve any classification of matter. In the early volumes of Psyche the attempt was made to bring together the whole contents of volumes in a continuous record, but the disadvantages of the plan were found to overbalance its advantages. In such a plan the whole contents of a volume must be held back until the volume is finished, and other works which are connected with the former by cross-references must be postponed to them. This plan has few advantages, moreover, as reference is rarely made to the contents of works by volumes. In later volumes of PsYche little or no attempt has been made at the classification of matter.

The whole problem of classification is solved by the publication of the record in form suitable for the construction of card catalogs. The only feature of the work which is marred by the card catalog arrangement is the sequence of the current numeros used for the purposes of the index.

Some persons will choose to arrange their card catalogs by subjects, and others in chronological order, but I have 
found the most convenient arrangement to be that by authors, alphabetically and with titles arranged alphabetically under the names of the authors, the index being relied on for reference by subjects or in any other manner desirable. This requires, so long as the index is made by the use of the current numeros, the preservation of a copy of the record in its original form.

During the past three years I have been engaged, amidst other duties, in writing that bibliography of economic entomology which was projected by the United States entomological commission in $\mathrm{I} 88 \mathrm{I},{ }^{1}$ and was turned over to the United States Department of agriculture upon the extinction of the commission. This I have prepared strictly in accord with the methods adopted in Psyche, and I have hopes that it may appear so, when published. It has been necessary to index this in large part in advance of its publication, and while yet it was in process of formation, so that the current numeros were not yet attached to it. Under these circumstances the reference has been made in every case by the citation of the name of the author and of the title of the article. This method of reference, though less compact than the mere citation of a numero, has the advantage of being universally applicable, wherever the title may be found under the author's name.

The convenience of reference by a single series of numeros to the whole of the bibliography, however extensive it may become, seems to me one of the

\footnotetext{
${ }^{1}$ Circular 12 of U. S. entomological commission, January ist, 1884 .
}

most desirable features to be embodied in such a work.

One of the greatest objections to the annual records of literature, or to any other partial bibliography, from a bibliographical standpoint, is in the necessity, there present, of consulting many indices to find all the references to a single subject. No other form of reference is so compact, so definite and by so easily understood a symbol, as a simple numerical reference. With such means of reference available, new indices, complete to date, can be published from time to time, more readily than under any other circumstances.

I have now sketched briefly to you a few thoughts upon the desirable features of a permanent, complete, simple bibliography, convenient of reference. I have assumed that the characteristics of such a bibliography, are to be found in Psyche. It is true that the Bibliographical record of Psyche is not complete, but that is not the fault of its plan; only the misfortune of its circumstances. However unreasonable it may be to hope that these circumstances will yet so change, that the record in Psycine may be made complete, I still hope it may see better days. If I am not astray in my appreciation of it, it will at least serve as a model.

I hope yet to see an index to the literature of entomology, which will embody the features I have set forth, or better ones. Such a work could well be undertaken in connection with the work of some scientific station where entomology is a special feature, and which is provided with the necessary means 
for its accomplishment. And if so undertaken and carried out, it should be a work which could be pointed at with pride. I would fain see this club the author of it.

I would gladly have contributed to your meeting a more worthy address, but beg you to remember that if not felicitous of speech I am constant of heart, and shall ever wish you prosperity and good fellowship in your future.

Respectfully, B: Pickman Mann.

\section{SEXUAL ATTRACTION IN PRIONUS.}

BY ANNA KATHERINA DIMMOCK, CAMBRIDGE, MASS.

Late in the summer of 1883 my attention was drawn to the sudden appearance of a large number of holes in the garden, which, upon closer observation, proved to be the exits of numerous beetles of the genus Prionus. Having heard that the attraction of the male by the female was not common among coleoptera, and finding no notice of such attraction in the above-mentioned coleoptera, I captured a large female which was found in the grass with ovipositor distended and greatly protruded. Scarcely had the female been secured before a male Prionus appeared; he ran and flew, by alternation, meanwhile rapidly palpitating his antennae, about and around the tent, inside of which the female had been confined; finally, discovering the entrance to the tent, he flew in and lit directly on the screen under which the female had been put. After the appearance of the first male another was seen to approach the tent. He went through a similar performance to that of the first one, finally alighting on the cage. In this manner a great many male specimens of Prionus were taken in the course of an afternoon. On account of the presence of so many males a number of females made their appearance, showing an attraction of the female to the male like that above-noted of males attracted by females. Instances similar to those just described, that is, of male insects attracted by females of the same species, have been frequently recorded in lepidoptera, especially among the bombycidae; but among the coleoptera such cases are, I think, more rarely met with, the only instance to my knowledge being the one originally mentioned by Prof. F. H. Snow, ${ }^{1}$ and quoted by Mr. J. A. Lintner. ${ }^{2}$ Prof. Snow found males of Polyphylla variolosa vigorously scratching the ground above places where females were about to emerge, presumably guided to these places, as Mr. Lintner suggests, by the sense of smell, rather than, as Prof. Snow supposed, by that of hearing.

The most remarkable part of the sexual attraction manifested by Prionus is that of the females being attracted by the males, a kind of attraction concerning which I have found no notice whatever. 2 Mar. 1884.

1 Trans. Kans, acad. sci., 1874 , p. $27-28$.

2 Lintner, ist ann. rept. insects N. Y., 1882 [1883], p. 71. 

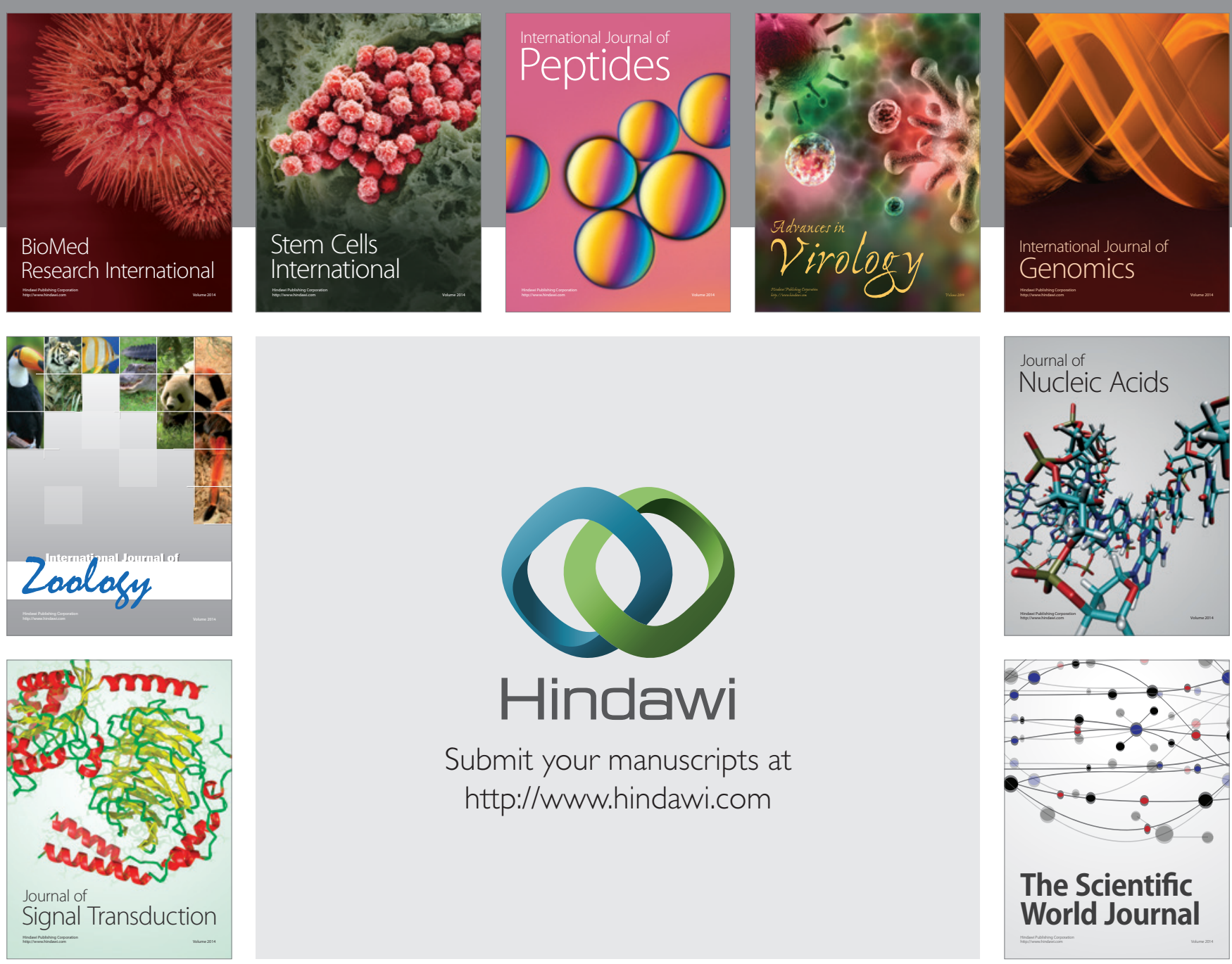

Submit your manuscripts at

http://www.hindawi.com
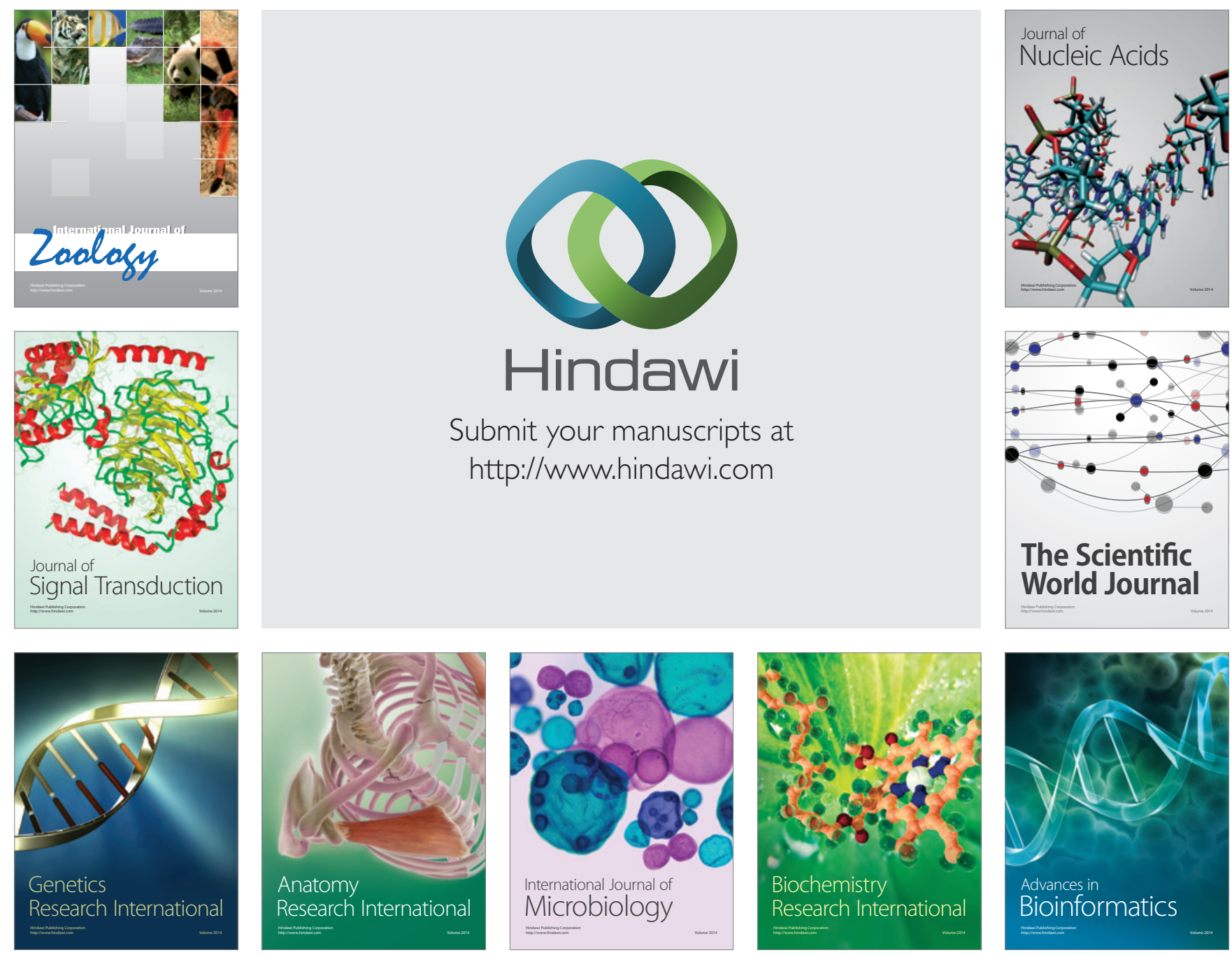

The Scientific World Journal
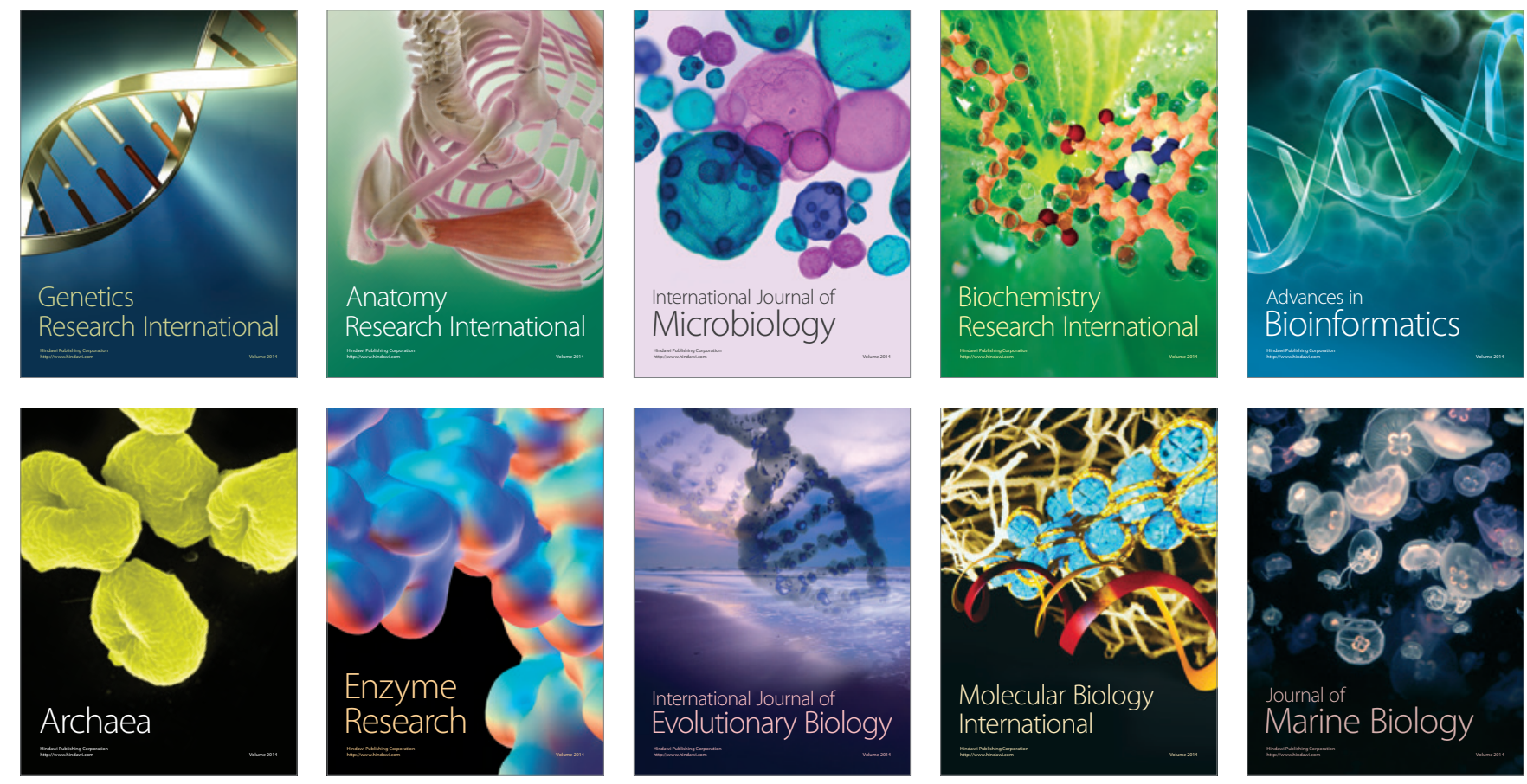